\title{
Innovation Culture and Education
}

\author{
Larisa Mylnikova \\ Smolensk State University \\ Smolensk, Russia
}

\begin{abstract}
The article considers the issue of formation of innovative culture among the population during reforming the education system and stimulating the transition of Russia to the economy based on knowledge, or innovative economy. It is shown that an innovative culture, which is implemented through the educational system, is the driving force and the result of effective changes. The conclusion describes the necessity of conducting educational activities of all segments of population in the issues of innovative culture because culture awakens human initiative to create new ideas as well as goods and services.
\end{abstract}

Keywords-innovation; culture; education; knowledge; science; innovative economy

\section{INTRODUCTION}

The process of searching for the optimal strategy for the country's transition to a highly effective economic growth, to provision of modern and decent standards of living for population has brought up the issue of comprehensive studying of theoretical foundations of innovative development, as well as the issue of solutions aimed at creating an innovative susceptibility, which can be implemented through the educational system.

The article defends the position of relevance of the formation of culture of innovation during learning and involves the stimulation of innovative activity, specification of the decisions taken based on knowledge and capabilities of the subjects of market economy, focuses on increased attention to the condition and needs of actual participants in the innovation processes. This helps to exclude the currently dominant and abstractly simplified understanding of the possibilities and methods of innovation activity in the country (region); to see the issue in all facets and make the transition to systematic positions when making decisions about building an innovative economy in Russia. The author draws attention to the particular importance of education in forming a culture of innovation. Innovations occur in a particular institutional context and educational institutions significantly affect their formation, intensity and content.

The problem of creating a culture of innovation is considered to be one of the priorities of public policy at the stage of educational system and economy modernization. The main purpose of the article is the theoretical basis of formation of a culture of innovation, developing psychological susceptibility of society to innovation within all segments of the population through educational system.
The object of research is culture of innovation and creation of national economy. The subject of research is economic relations arising between different economic agents during formation of culture of innovation.

The methodological base of research consists of the methods of traditional and new political economy, methodological principles of the system approach and evolutionary theory. The study is based on the principles of unity of historical and logical, as well as critical and analytical approach to the analysis of economic phenomena.

The study reinterpreted the concept of "innovation". Innovation is a complex, creative and unsafe process of change in the innovation culture, the existing knowledge on the implementation and commercialization of the best in its properties to the products.

It is established that in the modern institutional environment the emergence of innovative breakthrough is possible only at formation of innovative culture of the population that is a priority and a major accelerator of development in a purposeful state innovation policy.

\section{INNOVATION CULTURE, INNOVATION AND EDUCATION IN THE SYSTEM OF SOCIO-ECONOMIC RELATIONS}

Culture of innovation represents the acquired knowledge, perceptions and experience of purposeful human learning, aimed to transform the environment and itself, the invention and introduction of innovations in different spheres with the aim of improving the welfare and intellectual development. It is a free creation of the new with adherence to the principle of continuity.

The concept of "innovation" first appeared in the works of scientists of the $19^{\text {th }}$ century and meant the introduction of individual elements of culture in a different environment. Despite the different approaches to the definition of innovation, what most scientists put at the forefront is the ability of innovation to change the existing conditions of production regarding creative human activity.

The fundamentals of modern theory of innovations are present in the works of Nikolai Kondratiev ${ }^{1}$, Joseph Schumpeter $^{2}$, Pitirim Sorokin ${ }^{3}$, Simon Kuznets ${ }^{4}$, Gerhard

\footnotetext{
${ }^{1}$ Nikolai Kondratiev, "About the Question of the Major Cycles of the Conjuncture"

${ }^{2}$ Joseph Shumpeter, "The theory of economic development: an inquiry into profits, capital, credit, interest, and the business cycle"

3 Pitirim Sorokin, "Social and Cultural Dynamics"
} 
Mensch $^{5}$, and are further developed in the works of contemporary foreign and Russian researchers.

For instance, Schumpeter treats innovation as a new scientific and organizational combination of factors of production, which is motivated by entrepreneurial ability and talent ${ }^{6}$. The new moment of dynamic economic development is hidden in the internal logic of the aforementioned innovations.

A.Harin and I.L.Kolensky define innovation as a result of creative activity and investment, which is aimed at the development, production and dissemination of new types of goods, services and technologies, organizational forms ${ }^{7}$. The most vivid expression of this approach is given by E.A.Utkin, who focuses on the fact that labour exists in the nature of the creative execution of new knowledge. Mr. Utkin also defines innovation as an object launched as a result of carrying out scientific research or discoveries; the object is significantly different from any previous analogue ${ }^{8}$.

According to A.A.Kuteynikov, innovation is a new way to meet public needs, based on the achievements of science and technology and giving the beneficial effects increase ${ }^{9}$. Here we see a narrower definition.

Basing on the aforementioned definitions of innovation in economic literature one can conclude that the current term is widely understood, and often contains different shades of meaning. The main determining condition for the emergence of innovation is obtaining the result of a set of actions, aimed at creation of a new product or a service (or an improved one), or a process demanded by the market. First of all, it is the result of changes in the culture of innovation, in the current array of knowledge. This result leads to a change in the existing technology, operations management and brings financial benefits. This will ultimately result in creating new level of a product value. However, one should note that innovation, culture and education are interconnected in the aspect of production, science, technology and economics.

The existing level of cultural innovation in Russia, which was formed during the removal of the command system and the "primitive accumulation of capital", was not able to create the conditions for the process of creation. Today, the tasks that the country faces have changed; herefore, a reform is necessary, which aims at bringing up a generation, capable of expanding and improving their knowledge and technologies.

One of important factors in the development of innovative economy is the prevailing culture, which stimulates innovative activity, includes several components

\footnotetext{
${ }^{4}$ Simon Kuznets, "Secular Movements in Production and Prices"

${ }^{5}$ Gerhard Mensch, "Stalemate in Technology: Innovations Overcome the Depression"

${ }^{6}$ Joseph Shumpeter, "The theory of economic development: an inquiry into profits, capital, credit, interest, and the business cycle"

${ }^{7}$ Harin A.A., Kolensky I.L. Innovative management // M.:Higner School. 2003- P.35

${ }^{8}$ Utkin E.A., Morozova G.I., Morozova N.I. Innovative management // M.:Akalis. 1996. Pp.5-9.

${ }^{9}$ Kuteinikov A. A. Technological innovation in the U.S.

economy//Moscow: Nauka. 1990 - Pp. 12, 13.
}

(legal culture, managerial culture, entrepreneurial culture and corporate culture). These components are formed in the process of improving knowledge and skills in the aspect of consuming education services.

Education is one of the major subsystems of the social sphere of the state; the one which provides getting systematic knowledge and skills so that people were able to effectively use them in their professional activities. On the one hand, educational activity can be characterized as labour, on the other hand, it can be named creativity. Thorough development of personality is the main objective of he above-mentioned educational activity.

The Federal law №273 (dated 29th December, 2012) "On Education in the Russian Federation" provides the following definition of education: "a united purposeful process of education and training which is proved to be an important public good and carried out in the interests of a person, a family, society and state; as well as a set of acquired knowledge, skills, values, experience and competence of certain size and complexity in order to develop a person intellectually, spiritually, morally, creatively, physically and (or) professionally."

Education is the most important source of economic growth of a country, social stability, an indicator of the quality and safety of the population life. A few educated people are enough to give impetus to economic development based on knowledge. However, to make such impetus in the form of new industries and technologies, goods and other products appear, it is necessary to train a sufficiently large number of people, while the most talented and creative ones will be able to stand out. In addition, new production facilities should be operated by people who possess the knowledge and the culture of innovation. Economic growth without education cannot be discussed; therefore, in this case it clearly has primacy and priority. The core purpose of educational structure is thorough development of a person, their creativity and innovative abilities.

The educational sector produces and distributes goods (knowledge, outlook, cultural experience) and is one of the most promising sectors of economy. It plays a special role in a country's development as it promotes the development of innovations that improve a country's competitiveness and allow it to obtain a special niche in the world market. This is the most promising area of activity and the only sector of the economy, which contributes to a culture of innovation of highly qualified specialists for all branches of the national economy.

\section{InNOVATIVE CUlture AS THE Dominant FEATURE OF THE DEVELOPMENT OF THE NATIONAL ECONOMY}

In its most general definition, culture represents education, a set of rules, regulations, modes of action, communication skills, experience factors. In any culture, in addition to a traditional layer, there is an innovative one. In this case, a culture can act, on the one hand, as a unity of continuity and renewal, which suggests the use of cultural values, accumulated by ancestors and carefully preserved by descendants, and, on the other hand, as traditional changes 
consistent with the spirit of time, the growth of human capital with the consumption of education services, the pursuit of scientific and technological excellence, or innovations.

Innovations are needed for social development. Both tradition and innovation are interconnected and interdependent to such an extent that sometimes they are difficult to distinguish. Just as there are traditions and customs, innovation is initially the product of transformation of knowledge into economic benefit. They are gradually adopted and become a part of history as generations change over time. A civilization's ability to change largely determines the possibility of development. If the internal or external circumstances and the degree of knowledge create within society those needs that cannot be met on the mere basis of traditions of this system, it leads to their transformation or even the replacement of traditions by innovations.

The very mentality of the ethnic group is a collection of ethnic, cultural and social skills, spiritual settings, stereotypes and a set of skills and public installations, stereotypes, which are formed by crystallization of previous business experience and its organizational, logistical and technological features in human memory. That is the reason why not all innovations take root in society (this is especially true for the borrowed ones). All innovations take a kind of selection in terms of their consistency or inconsistency with mental attitudes, traditional values, education; they are accepted or rejected depending on how the "new" corresponds to the "old" and on the relevance of social development.

A culture, which is formed during education of professionals, the economy and the innovation process are closely linked and are responsible for mutual development. There is no doubt that the intensity and effectiveness of the innovation process in economy are affected by knowledge and cultural features of society. Culture of innovation reflects a person's orientation, enshrined in their motivation, knowledge, skills, social norms. This is the process of a targeted society training in order to get ready for a new invention, implementation and comprehensive development of innovations in various areas of life in compliance with the principle of continuity. Culture of innovation can also be represented as a professional phenomenon because it is a professional, no matter what industry they operate, who introduces new ideas in various spheres of public life labour, life, leisure, learning and communication. Culture of innovation is the basis of forming information economy and innovative one. Culture of innovation awakens people's initiative to create new ideas, their willingness and ability to support and implement innovations in all spheres of life, their responsibility associated with the achievement of objectives of innovation.

As a special form of human culture, it is directly linked to other forms, primarily legal culture, administrative culture, entrepreneurial culture and corporate culture. A culture of innovation can make a significant impact on the entire culture of professional work and industrial relations. It should be noted that innovations in any society are more effective if they are backed up by legislation. A high level of legal culture raises without doubt self-organization of people, which has a positive effect on the results of innovative process. Administrative culture expresses the relation to innovative process and thereby determines the ability to adapt and to develop systems of social production control. At different times and in different situations it can induce and retard innovative management processes. Corporate (organizational) culture is a tool that allows to ensure the effectiveness of the business process. It contributes to the choice of the best variant of business interactions of employees with the priority of innovative trends. The development of an entrepreneurial culture defines the relationship of an individual and society to innovative entrepreneurship. This entrepreneurship contributes to the creation of an optimal structure of the economy and the acceleration of innovation processes. Within a market economy it is flexible and adaptable to changing conditions of financial and economic activity; it contributes to the development of competition; solves the problem of unemployment; reduces social tensions. Innovative entrepreneurship has a high scientific potential, is an essential participant of the market economy which performs crucial economic functions. Social acceptance or rejection of innovative entrepreneurship depends on culture of innovation, socio-cultural status of subjects and is connected with history of development.

Solving the challenges aimed at the development of innovative economy, thus enabling a country to take its rightful place in international division of labour and provide modern standards of living for population means direct dependence upon the social susceptibility to culture of innovation, the degree of cultural development of the population formed by means of education. Only the highest priority of education and carrying out the tasks of innovative development of the population can provide the necessary level of development of a country.

Economic development of modern Russia is determined by various ministries and departments, which are responsible for scientific, technical, economic and innovative potential of the country. In addition, scientific activities are carried out by various organizations dealing with education, science and production of innovative goods. These organizations simultaneously implement the following:

- education of society which is receptive to innovation;

- development of projects related to the development of various technologies, companies, sectors and industries of the national economy;

- fundamental and applied studies;

- development and use of new technologies in the educational process.

Recognising innovation at the level of government as a vital factor of economic development has led to the stimulation of innovative development by investing in education and science. On condition that these investments 
are stable or growing, they show returns in the long term. The aforementioned recognition has also led to creation of departments responsible for innovation policy, which are specifically focused on solving all issues.

\section{CONCLUSION}

As a result of studying the culture of innovation and a variety of theoretical approaches to innovation its relationship with education has been defined. It can be said that innovation is a complex, creative and risk-involving process of change for the implementation and commercialization of the best product or service (based on its properties) for all sectors of society in a competitive market. This is primarily a change in culture and the existing array of knowledge, which entails changes in the existing technology and operation management while bringing economic benefits. Ultimately, it is the result of education in the form of public sensitivity and the creative process in the creation of new values.

The government is aware of the fact that the transition to an innovative way of development is connected with largescale investments in innovative education of people, their culture of innovation and promotion of innovative activity. Human development is the main goal and a necessary condition for innovative development, enabling further technological innovation. It is our absolute national priority both the current one and the long-term one.

Long-term tasks have been identified, which include developing an innovative susceptibility of population, innovative spirit to major technological innovations of the new technological order, which transforms consumption patterns and behavior of population. Without formation of innovative consciousness population will reject innovations, which will lead to the difficulty of their implementation. Formation of an innovative society predetermines the institutional development model that takes into account culture of innovation, education, moral responsibility, as well as economic one and social one. It is a self-organizing and self-aware society, the society of creative individuals.

Most foreign and domestic researchers point out that trends in the development of innovative society depend on the degree of innovative knowledge formed by means of education. Forming a culture of innovation should become an important challenge of the next few years, as the creation of conditions suitable for preservation and development of the educational system, which produces and develops creativity, thus being a fundamental component of innovative development. Education is a real means of efficiency of innovative economy. Taking this into account, it is necessary to promote the creation of innovative universities within federal districts and regions. The educational system should include innovative methods and educational technologies as well as active involvement of university professors and students into the development of projects at the level of federal districts and regions. In general, the present situation in Russian economy is caused by the deterioration of vocational-quality workforce and the process of scientists' emigration. Aspects which negatively affect innovative development include the low level of culture of innovation and innovative education. Consequently, research and innovation are marked with a low social status; there is lack of personnel able to perform the functions of managers of innovation, lack of consulting engineers; lack of structure in innovative terminology; lack of a unified state system of supporting innovation with information; protection of intellectual property; lack of an institution which supports and coordinates innovative entrepreneurship. In addition, the state budget deficit contributes to the problem; so do the cost of subsidising enterprises lagging behind, inadequate tax policies; these issues exacerbate the technological crisis, which has already had a profound effect on Russian Federation.

It was determined that innovative level of regional development can be considered only on condition that the regions mentioned possess enough autonomy in forming their own innovation policy. It seems that the priority objective must be the training of psychological social susceptibility to innovation. Human distrust of innovations, which is present at the subconscious level, is the primary negative factor affecting innovative development. This needs to be taken into account while forming a long-term innovation policy. The necessity of educating all segments of population in matters of innovation receptivity can be achieved through the educational system by introducing an appropriate course of lectures, by creating innovative regional centres or university consortia ${ }^{10}$. It is established that in the modern institutional environment the emergence of innovative breakthrough is possible only at formation of innovative culture of the population that is a priority and a major accelerator of development in a purposeful state innovation policy.

\section{REFERENCES}

[1] The Federal law №273 (dated 29th December, 2012) (as amended on 03.07.2016, Rev. from 01.01.2017) "On Education in the Russian Federation"

[2] Nikolai Kondratiev, "About the Question of the Major Cycles of the Conjuncture and the theory of forecasting" - M.: Economy, 2002.

[3] A. Kuteinikov A. Technological innovation in the U.S. economy//Moscow: Nauka. 1990-Pp. 12, 13.

[4] Kuznens S. Secular Movements in Production and Prices. New York, 1930.

[5] Mensch Gerhard. Stalemate in Technology: Innovations Overcome the Depression. Cambridge, Massachusetts, 1979.

[6] L. A Mylnikova. Background and evaluation of the local climate the economic system. Bulletin of the Moscow University of S. U. Vitte. Bulletin of the Moscow University of S. U. Vitte. 2014'4(10)

[7] Sorokin P. Social and cultural dynamics. - SPb.: RGGU, 2000.

[8] Utkin E. A., Morozova G. I., Morozova N. I. Innovation management//Akalis M. 1996.

[9] A. A. Kharin, I. L. Kolinski Innovation management// M.: Higher school. 2003 - p. 35.

[10] Schumpeter, J. A.. The theory of economic development. - M., 1982.

\footnotetext{
${ }^{10}$ Mylnikova L. A. Background and evaluation of the local climate the economic system. Bulletin of the Moscow University named S. U. Vitte. Bulletin of the Moscow University of S. U. Vitte. 2014'4(10)
} 